\title{
Differential Activation of Extracellular Signal-Regulated Protein Kinase in Primary Afferent Neurons Regulates Brain-Derived Neurotrophic Factor Expression after Peripheral Inflammation and Nerve Injury
}

\author{
Koichi Obata, ${ }^{1,2}$ Hiroki Yamanaka, ${ }^{1}$ Yi Dai, ${ }^{1}$ Toshiya Tachibana, ${ }^{1}$ Tetsuo Fukuoka, ${ }^{1}$ Atsushi Tokunaga, ${ }^{1}$ \\ Hideki Yoshikawa, ${ }^{2}$ and Koichi Noguchi ${ }^{1}$ \\ ${ }^{1}$ Department of Anatomy and Neuroscience, Hyogo College of Medicine, Nishinomiya, Hyogo 663-8501, Japan, and ${ }^{2}$ Department of Orthopaedic Surgery, \\ Osaka University Medical School, Osaka 565-0871, Japan
}

To investigate the intracellular signal transduction pathways involved in regulating the gene expression of brain-derived neurotrophic factor (BDNF) in primary afferent neurons, we examined the activation of extracellular signal-regulated protein kinase (ERK) in dorsal root ganglion (DRG) neurons after peripheral inflammation and sciatic nerve transection. Peripheral inflammation induced an increase in the phosphorylation of ERK, mainly in tyrosine kinase A-containing small-to-medium-diameter DRG neurons. The treatment of the mitogen-activated protein kinase (MAPK) kinase 1/2 inhibitor U0126 reversed the pain hypersensitivity and the increase in phosphorylated-ERK (p-ERK) and BDNF in DRG neurons induced by complete Freund's adjuvant. On the other hand, axotomy induced the activation of ERK mainly in medium- and large-sized DRG neurons and in satellite glial cells. U0126 suppressed the axotomy-induced autotomy behavior and reversed the increase in p-ERK and BDNF. The intrathecal application of nerve growth factor (NGF) induced an increase in the number of p-ERK- and BDNF-labeled cells, mainly small neurons, and the application of anti-NGF induced an increase in p-ERK and BDNF in some medium-to-large-diameter DRG neurons. The activation of MAPK in the primary afferents may occur in different populations of DRG neurons after peripheral inflammation and axotomy, respectively, through alterations in the target-derived NGF. These changes, including the changes in BDNF expression, might be involved in the pathophysiological changes in primary afferent neurons.

Key words: mitogen-activated protein kinase; extracellular signal-regulated protein kinase; brain-derived neurotrophic factor; dorsal root ganglion; complete Freund's adjuvant; axotomy

\section{Introduction}

Extracellular signal-regulated protein kinase (ERK) is a mitogenactivated protein kinase (MAPK) that mediates several cellular responses to mitogenic and differentiation signals (Lewis et al., 1998). MAPK is activated by diverse extracellular stimuli, including several hormones and growth factors. Several groups have recently used immunohistochemistry and phosphospecific antisera to analyze the distribution and level of activation of signaling components in dorsal root ganglion (DRG) neurons in vivo (Kenney and Kocsis, 1998; Delcroix et al., 1999; Aley et al., 2001; Averill et al., 2001; Ma et al., 2001). Very recently we reported that phosphorylation of ERK in primary afferent neurons occurred in response to noxious stimulation of the peripheral tissue or electrical stimulation to the peripheral nerve, i.e., activity-dependent

\footnotetext{
Received Dec. 4, 2002; revised March 6, 2003; accepted March 6, 2003.

This work was supported in part by grants-in-aid for scientific research and a grant from the Open Research Center, Hyogo College of Medicine, from the Japanese Ministry of Education, Science, and Culture. We thank Yuki Obata, Nobumasa Ushio, and Kimiko Kobayashi for technical assistance. We thank Dr. D. A. Thomas for correcting the English usage.

Correspondence should be addressed to Dr. Koichi Noguchi, Department of Anatomy and Neuroscience, Hyogo College of Medicine, 1-1 Mukogawa-cho, Nishinomiya, Hyogo 663-8501, Japan. E-mail: noguchi@hyo-med.ac.jp. Copyright $\odot 2003$ Society for Neuroscience $\quad 0270-6474 / 03 / 234117-10 \$ 15.00 / 0$
}

activation of phosphorylated ERK in DRG neurons (Dai et al., 2002). In the present study, we examined whether the phosphorylation of ERK increases in vivo in DRG neurons in the experimental peripheral inflammation model induced by complete Freund's adjuvant (CFA). Sciatic nerve injury results in distinct changes in sensory neurons of the DRG and their terminals in the spinal cord (Woolf and Salter, 2000). In the adult, a sciatic nerve lesion leads to a reduction in substance $\mathrm{P}(\mathrm{SP})$ and calcitonin gene-related peptide (CGRP), neurotransmitters for small nociceptive sensory neurons, and an increase in neuropeptide $Y$ in large sensory neurons (Hokfelt et al., 1994; Noguchi et al., 1995). Therefore, we also investigated the changes in the phosphorylation of ERK that occur in primary sensory neurons after nerve injury.

Brain-derived neurotrophic factor (BDNF) synthesis is known to increase in tyrosine kinase A (trkA)-expressing smalland medium-sized DRG neurons after peripheral inflammation (Apfel et al., 1996; Michael et al., 1997; Kerr et al., 1999; Mannion et al., 1999; Thompson et al., 1999). In contrast, after sciatic nerve transection, the increase in BDNF occurs in the axotomized medium-to-large-diameter DRG neurons (Cho et al., 1998; Tonra et al., 1998; Li et al., 1999; Michael et al., 1999; Zhou et al., 1999). On the other hand, the ERK in the nervous system produces not only short-term functional (nontranscriptional) 
changes by phosphorylating kinases, receptors, and ion channels, but also long-term adaptive changes by activating transcriptional factors. For example, activated ERK translocates from the cytoplasm to the nucleus and activates Rsk2, which then phosphorylates the transcription factor cAMP response element-binding protein (CREB), subsequently activating cAMP response element (CRE)-mediated gene expression (English and Sweatt, 1997; Atkins et al., 1998; Impey et al., 1998, 1999; Obrietan et al., 1999). However, apart from immediate early genes such as c-fos, the specific target genes regulated by ERK are primarily unknown (Xing et al., 1996; Sgambato et al., 1998; Ji et al., 2002a). The second objective of the present study was to investigate whether the ERK pathway plays a role in regulating the expression of BDNF in the DRG and pain-related behavior after peripheral inflammation and after sciatic nerve transection. Furthermore, the possible relationship between NGF and BDNF expression in primary afferent neurons in these two models was also examined and discussed.

\section{Materials and Methods}

Animals. A total of 109 male Sprague Dawley rats weighing 200-250 gm were used. All animal experimental procedures were approved by the Hyogo College of Medicine Committee on Animal Research and were performed in accordance with the National Institutes of Health guidelines on animal care.

Surgical procedures. All experimental procedures were done on rats that were deeply anesthetized with sodium pentobarbital $(50 \mathrm{mg} / \mathrm{kg}$, i.p.). Additional doses of the anesthetics were given as needed. In all rats, no surgery was performed on the right side. Special care was taken to prevent infection and to minimize the influence of inflammation. The hair of the rat's lower back and thigh was shaved and the skin was sterilized with $0.5 \%$ chlorhexidine and covered with clean paper. Sterile operating instruments were used.

For peripheral inflammation, the animals received a subcutaneous injection of $100 \mu \mathrm{l}$ of CFA ( $0.1 \%$ heat-killed Mycobacterium butyricum; Calbiochem, La Jolla, CA) diluted 1:1 with saline into the plantar surface of the left (ipsilateral) hindpaws. Animals were allowed to survive for 1, 3, or $7 \mathrm{~d}$ after surgery $(n=4$ for immunohistochemistry and $n=4$ for Western blotting for each time point). For sciatic nerve transection, the left sciatic nerve was exposed and ligated at the midthigh level. Distal to this, the nerve was cut and a segment of $1.5-2.0 \mathrm{~cm}$ was removed. Animals were allowed to survive for 3,7 , or $14 \mathrm{~d}$ after surgery $(n=4$ for immunohistochemistry and $n=4$ for Western blotting for each time point). Rats without surgery $(n=8)$ were used as naive controls for immunohistochemistry and Western blotting.

The intrathecal delivery of NGF or anti-NGF was performed basically as described previously (Fukuoka et al., 2001). A laminectomy of the L5 vertebra was performed under adequate anesthesia with sodium pentobarbital. The dura was cut, and a soft tube (Silascon; outer diameter, 0.64 $\mathrm{mm}$; Kaneka Medix, Osaka, Japan) was inserted into the subarachnoid space for an $\sim 1.5 \mathrm{~cm}$ length so that its tip lay over the lumbar enlargement, and $10 \mu \mathrm{l}$ of recombinant rat $\beta$-NGF (10 $\mu \mathrm{g}$ in $10 \mu \mathrm{l}$ of normal saline; R \& D Systems, Minneapolis, MN) or sheep anti-NGF antibody (10 $\mu \mathrm{g}$ in $10 \mu \mathrm{l}$ of normal saline; Chemicon Temecula, CA) was administered. Normal saline was used as vehicle control. Rats were allowed to survive for up to $3 \mathrm{~d}$ after surgery ( $n=3$ for immunohistochemistry and in situ hybridization histochemistry and $n=4$ for Western blotting).

For sustained intrathecal drug delivery, an mini-osmotic pump (Alzet type $1003 \mathrm{D}$ or type 2001; Durect Co., Cupertino, CA) that operates at a rate of $1 \mu \mathrm{l} / \mathrm{hr}$ for a period of 3 or $7 \mathrm{~d}$ was filled with the MAPK kinase (MEK) $1 / 2$ inhibitor U0126 (0.05 or $0.5 \mu \mathrm{g} / \mu \mathrm{l}$; Calbiochem), in 50\% DMSO; the catheter of the pump was implanted intrathecally at least $3 \mathrm{hr}$ before CFA injection or sciatic nerve injury. DMSO (50\%) was used as a vehicle control. After surgery, the wound was washed with saline and closed in layers (fascia and skin) with 3-0 silk thread. Rats were allowed to survive for up to 3 or $7 \mathrm{~d}$ after surgery ( $n=4$ for immunohistochemistry and in situ hybridization histochemistry; $n=4$ for Western blotting).

Behavioral tests. For peripheral inflammation, all rats were tested for mechanical allodynia and heat hyperalgesia of the plantar surface of the hindpaws $1 \mathrm{~d}$ before surgery and daily thereafter for $3 \mathrm{~d}$ until they were killed, as described previously (Miki et al., 2000). The frequency of paw withdrawal in response to normally innocuous mechanical stimuli was measured using a von Frey filament of $23.0 \mathrm{mN}$. The von Frey filaments were applied from underneath the metal mesh floor to the plantar surface of the paw for five trials for each paw at $\sim 3$ min intervals. Each trial consisted of six maximal repetitive stimuli with a frequency of $\sim 2 \mathrm{~Hz}$ or until a paw withdrawal response was observed. The occurrence of paw withdrawal was expressed as "response frequency" (i.e., number of trials accompanied by paw withdrawal per 5 trials $\times 100$ ).

Heat hypersensitivity was tested using the plantar test (7370, Ugo Basile, Comerio, Italy). A radiant heat source beneath a glass floor was aimed at the plantar surface of the hindpaw. Three measurements of latency were taken for each hindpaw in each test session. The hindpaws were tested alternately, with intervals between consecutive tests of $>5$ min. The three measurements of latency per side were averaged and a difference score was computed by subtracting the average latency of the contralateral side from that of the ipsilateral side. Negative difference scores indicated a hyperalgesic response on the ipsilateral side.

Data are expressed as means \pm SEM. Differences in changes of values over time of each intrathecal group were tested using pairwise comparisons ( $t$ test). Differences of values between the intrathecal groups were tested using one-way ANOVA, followed by individual post hoc comparisons (Fisher exact test). A difference was accepted as significant if $p<0.05$.

For sciatic nerve transection, all rats were tested for autotomy behavior $1 \mathrm{~d}$ before surgery and daily thereafter for $7 \mathrm{~d}$ until they were killed. Signs of autotomy behavior (i.e., self-mutilation) were recorded for every digit using the following scale: 0 , no signs of self-mutilation; 1 , a tip of the nail removed with signs of old or fresh blood on or under the nail; 2 , a nail totally removed and damage to the distal portion of the digit; 3 , damage to the whole digit or the footpad. The graded scale used was similar to one used by Wiesenfeld and Hallin (Wiesenfeld and Hallin, 1983; BileviciuteLjungar and Lundeberg, 2000). In our study each digit was multiplied by the scale number and a total score value for each rat was obtained; then the mean \pm SEM across animals was determined. Differences of values between the intrathecal groups were tested using pairwise comparisons ( $t$ test).

Immunohistochemistry. The rats were deeply anesthetized with sodium pentobarbital and perfused transcardially with $1 \%$ paraformaldehyde in $0.1 \mathrm{M}$ phosphate buffer ( $\mathrm{PB}$ ) ( $\mathrm{pH} 7.4$ ), followed by $4 \%$ paraformaldehyde in $0.1 \mathrm{M} \mathrm{PB}, 1,3,7$, or $14 \mathrm{~d}$ after surgery ( $n=4$ at each time point). The left L4/5 DRGs were dissected out and processed for phosphorylatedERK (p-ERK), trkA, neurofilament (NF) 200, glial fibrillary acid protein (GFAP), activating transcription factor 3 (ATF3), and BDNF immunohistochemistry according to the procedure used in our previous study (Noguchi et al., 1995). The polyclonal primary antibody for the p-ERK1/2 (1:400; New England Biolabs, Beverly, MA), the trkA (1:500; Chemicon), the GFAP (1:400; DAKO, Glostrup, Denmark), the ATF3 (1:200; Santa Cruz Biotechnology, Santa Cruz, CA), and the BDNF (1: $400,1 \mu \mathrm{g} / \mathrm{ml}$; a gift from Amgen, Thousand Oaks, CA) and the monoclonal primary antibody for the NF200 (1:400; Sigma, St. Louis, MO) were used for DAB staining. For the double immunofluorescence staining for p-ERK1/2 and trkA, NF200, GFAP, or ATF3 and for BDNF and p-ERK1/2 or trkA, the tyramide signal amplification (NEN, Boston, MA) fluorescence procedures (Michael et al., 1997; Obata et al., 2002, 2003) were used to detect staining for rabbit anti-p-ERK1/2 polyclonal antibody (1:10000; New England Biolabs) and for rabbit anti-BDNF polyclonal antibody (1:8000, $1 \mu \mathrm{g} / \mathrm{ml}$; a gift from Amgen).

The number of $\mathrm{p}$-ERK1/2- and BDNF-immunoreactive (IR) neurons per section was counted in the left DRG. The proportion of p-ERK1/2and BDNF-expressing DRG neurons was determined by counting the neuronal profiles that show distinctive labeling in the DRG sections. In each rat, four to six sections of the L4/5 DRG at each time point were selected randomly and 2000-3000 profiles were counted. An average 
percentage of p-ERK1/2- and BDNF-IR neurons, relative to the total number of neurons, was obtained for each animal across the different tissue sections; then the mean \pm SD across animals was determined. For the size-frequency histogram data, measurements of the area of positive neurons over selected tissue profiles were performed using a computerized image analysis system (NIH Image) and only neurons with clearly visible nuclei were used for quantification. To distinguish cell sizespecific changes, we divided the DRG neurons into small $\left(<600 \mu \mathrm{m}^{2}\right)$, medium $\left(600-1200 \mu \mathrm{m}^{2}\right)$, and large $\left(>1200 \mu \mathrm{m}^{2}\right)$ neurons according to their cross-sectional area. At least 300 p-ERK1/2- or BDNF-IR neuron profiles were measured in each group. Because a stereological approach was not used in this study, quantification of the data may represent a biased estimate of the actual number of cells and neurons. An assistant who was unaware of the treatment group of the tissue sections performed all counting.

Differences in changes of values over time of each group were tested using one-way ANOVA, followed by individual post hoc comparisons (Fisher exact test). Pairwise comparisons ( $t$ test) were used to assess differences of values between the intrathecal groups. A difference was accepted as significant if $p<0.05$.

In situ hybridization histochemistry. For the in situ hybridization histochemistry (ISHH), the tissue was sectioned (16 $\mu \mathrm{m}$ thick) with a cryostat, thaw-mounted onto Vectabond- (Vector Laboratories, Burlingame, CA) coated slides and stored at $-80^{\circ} \mathrm{C}$ until ready for use. The procedure for ISHH was basically the same as that used in a previous study (Yamanaka et al., 1999; Hashimoto et al., 2001). Briefly, the rat BDNF cRNA probe corresponding to nucleotides 2273-2579 was prepared. The sections were treated with $10 \mu \mathrm{g} / \mathrm{ml}$ proteinase $\mathrm{K}$ in $50 \mathrm{~mm}$ Tris- $\mathrm{HCl}$ and $5 \mathrm{~mm}$ EDTA for $3 \mathrm{~min}$ and acetylated with $0.25 \%$ acetic anhydride in $0.1 \mathrm{M}$ triethanolamine; then ${ }^{35}$ S-labeled RNA probe $(5 \times$ $10^{6} \mathrm{cpm} / \mathrm{ml}$ ) was placed on these sections overnight at $55^{\circ} \mathrm{C}$. Hybridized sections were rinsed in $5 \times \mathrm{SSC}, 5 \mathrm{~mm}$ DTT for $30 \mathrm{~min}$ at $65^{\circ} \mathrm{C}$; washed in high-stringency buffer for $30 \mathrm{~min}$ at $65^{\circ} \mathrm{C}$; and treated with $2 \mu \mathrm{g} / \mathrm{ml}$ RNase A for $30 \mathrm{~min}$ at $37^{\circ} \mathrm{C}$. Sections were rinsed, dehydrated in an ascending ethanol series, and air dried. For autoradiography, the sections were coated with NTB-3 emulsion (Eastman Kodak, Rochester, NY), diluted $6: 4$ with distilled water at $45^{\circ} \mathrm{C}$, and exposed for 2 weeks in lighttight boxes at $4^{\circ} \mathrm{C}$. After development in D19 (Eastman Kodak) and fixation in $24 \%$ sodium thiosulfate, the sections were rinsed in distilled water, stained with hematoxylin-eosin, dehydrated in a graded ethanol series, cleared in xylene, and coverslipped.

Western blotting. Tissue samples from the left L4/5 DRG were lysed by homogenizing in $200 \mu \mathrm{l}$ of lysis buffer containing $20 \mathrm{~mm}$ Tris- $\mathrm{HCl}, \mathrm{pH}$ 8.0, $150 \mathrm{~mm} \mathrm{NaCl}, 1$ mм EDTA, $1 \%$ NP-40, $2 \mathrm{~mm} \mathrm{Na}_{3} \mathrm{VO}_{4}, 0.5$ mм DTT, $1 \mathrm{~mm}$ PMSF, $1 \mu \mathrm{g} / \mathrm{ml}$ pepstatin, $5 \mu \mathrm{g} / \mathrm{ml}$ leupeptin, $9 \mu \mathrm{g} / \mathrm{ml}$ aprotinin, and $10 \%$ glycerol. Lysates were centrifuged at $14,400 \times g$ for $60 \mathrm{~min}$, and the concentration of protein in each sample (supernatant) was determined using the Bio-Rad dye binding. Samples with equal amounts of protein were then separated by $10-20 \%$ PAGE, and the resolved proteins were electrotransferred to Hybond-P Nitrocellulose (Amersham Biosciences, UK). Membranes were incubated with $5 \%$ nonfat milk in Tris buffer containing Tween 20 (TBST; $10 \mathrm{~mm}$ Tris-HCl, pH 8.0, $150 \mathrm{~mm}$ $\mathrm{NaCl}$, and $0.2 \%$ Tween 20 ) for at least $10 \mathrm{~min}$ at room temperature and incubated with either rabbit anti-total ERK1/2 polyclonal antibody (1: 1000; New England Biolabs) or rabbit anti-p-ERK1/2 polyclonal antibody (1:1000; New England Biolabs) at $4^{\circ} \mathrm{C}$ overnight. Membranes were then washed twice with TBST and probed with goat anti-rabbit IgG conjugated with horseradish peroxidase (Vector Laboratories) at room temperature for $2 \mathrm{hr}$. Finally, membranes were washed several times with TBST to remove unbound secondary antibodies and visualized using enhanced chemiluminescence (Boehringer Mannheim, Indianapolis, IN). Each experiment was repeated at least twice; the same results were obtained in all cases. The density of specific bands was measured with a computer-assisted imaging analysis system (ATTO Densitograph version 4.02, Tokyo, Japan) and normalized against a loading control (total ERK).

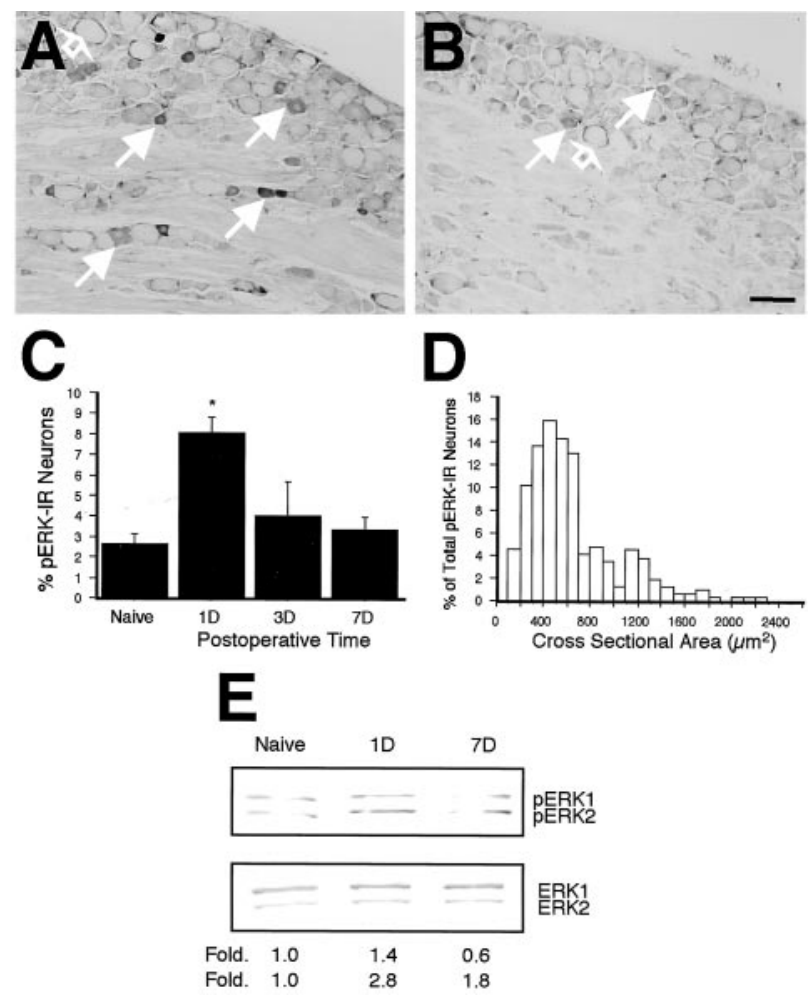

Figure 1. $A, B$, Photomicrographs showing the $p$-ERK-IR in the ipsilateral $(A)$ and contralateral $(B) L 4 / 5$ DRG $1 \mathrm{~d}$ after peripheral inflammation. There was an increase in the number of p-ERK-IR neurons in the ipsilateral DRG (large arrows). In contrast to DRG neurons, satellite cells show high basal levels of $\mathrm{p}$-ERK-IR (small open arrows). Scale bar: (in $B) A, B, 100 \mu \mathrm{m}$. C, Time course of the mean percentages of $p$-ERK-IR neurons relative to the total number of neurons in the L4/5 DRG. The mean percentages of $p$-ERK-IR neurons on the ipsilateral side significantly increased at $1 \mathrm{~d}$ after CFA injection compared with the naive control rats. ${ }^{*} p<0.05$ compared with the naive control. $D$, Size-distribution histogram of $p$-ERK-IR neuron profiles in the ipsilateral DRG $1 \mathrm{~d}$ after the CFA. At least 300 neuron profiles with visible nuclei were counted in four to six randomly chosen sections from two animals (two to three sections per animal). E, Western blot analysis of phosphorylated ERK and the total amount of ERK in the ipsilateral L4/5 DRG after CFA injection. CFA induced an increase in the intensity of the band for p-ERK at $1 \mathrm{~d}$. Bottom, Levels of total ERK, as loading controls. Fold. represents comparative levels over the naive control group after normalizing to the total ERK levels. The two rows of numbers correspond to measurements for ERK1 and ERK2. E, right, ERK1 corresponds to p44, and ERK2 corresponds to p42.

\section{Results}

\section{Increase in the phosphorylation of ERK after peripheral inflammation}

The CFA injection into the plantar surface of the hindpaw produced localized swelling, erythema, and hypersensitivity to mechanical and thermal stimuli that persisted for $3 \mathrm{~d}$ and were gradually resolved by $7 \mathrm{~d}$ after the injection. To examine the activation of ERK in DRG neurons, we used an antiserum to the phosphorylated form. The p-ERK-IR was located in neurons, as well as in surrounding satellite cells, as reported previously (Averill et al., 2001) (Fig. $1 A, B$ ). The p-ERK-IR neurons in the ipsilateral DRG $1 \mathrm{~d}$ after the CFA injection increased in terms of the number of labeled neurons and the intensity of labeling compared with those in the contralateral DRG. Most of these p-ERK-IR neurons were small-to-medium-diameter DRG neurons (Fig. 1 $A, B$ ). The intraplantar injection of saline $(100 \mu \mathrm{l})$ alone induced a very weak p-ERK induction (data not shown). The time course of change in the percentage of p-ERK-IR neurons is shown in Figure 1C. p-ERK-IR neurons of naive rats in the L4/5 DRG were $2.7 \pm$ $0.4 \%$ of the total neurons. The percentage of p-ERK-IR neurons on the contralateral side showed no change; however, inflamma- 
tion induced a significant increase in the percentage of p-ERK-IR neurons in the ipsilateral DRG at $1 \mathrm{~d}(8.1 \pm 0.7 \%)$, and the levels gradually declined and returned to normal by $3 \mathrm{~d}$ (Fig. $1 C$ ). One day after CFA-induced inflammation of the hindpaw, 184 of 315 p-ERK-IR neurons counted $(58.4 \%)$ were small and 98 $(31.1 \%)$ were medium (mean \pm SD of the cross-sectional area, $641 \pm 381 \mu \mathrm{m}^{2}$ ) (Fig. $1 D$ ). There was no difference in the percentage of p-ERK-IR neurons observed in the L4 and L5 DRG. The total amount of ERK1/2 and phosphorylated ERK1/2 in the ipsilateral L4/5 DRG after peripheral inflammation was determined by Western blotting (Fig. $1 E$ ). The CFA injection did not alter the level of total ERK protein, but increased the phosphorylation level of ERK1/2 in the ipsilateral DRG at $1 \mathrm{~d}$ compared with the naive control. Because ERK is activated only in a small subset of DRG neurons and is constitutively expressed in surrounding satellite cells, Western blotting may be less sensitive than immunohistochemistry for detecting ERK activation in the DRG.

\section{ERK activation mediates pain hypersensitivity and BDNF expression after peripheral inflammation}

We then investigated whether the inhibition of ERK activation modified inflammatory pain hypersensitivity, such as hyperalgesia and allodynia. The intrathecal administration of the MEK1/2 inhibitor U0126 via an osmotic pump (0.05 or 0.5 $\left.\mu \mathrm{g} \cdot \mu \mathrm{l}^{-1} \cdot \mathrm{hr}^{-1}\right)$ into noninflamed animals produced no significant changes in basal pain sensitivity (i.e., mechanical allodynia and thermal hyperalgesia; data not shown). In contrast, the intrathecal administration of U0126 $\left(0.5 \mu \mathrm{g} \cdot \mu \mathrm{l}^{-1} \cdot \mathrm{hr}^{-1}\right)$ significantly reduced both the inflammationinduced heat and mechanical hypersensitivity measured at $1 \mathrm{~d}$. A lower dose of U0126 (0.05 $\left.\mu \mathrm{g} \cdot \mu \mathrm{l}^{-1} \cdot \mathrm{hr}^{-1}\right)$ significantly inhibited only thermal hyperalgesia; the effect on the mechanical allodynia did not reach significance

(Fig. 2A,B). The total amount of ERK and phosphorylated ERK in both vehicle- and U0126-treated groups was also determined by Western blotting (Fig. 2C). The inflammation-induced increase in ERK phosphorylation was reversed by $\operatorname{U0126}\left(0.5 \mu \mathrm{g} \cdot \mu \mathrm{l}^{-1} \cdot \mathrm{hr}^{-1}\right)$. To examine whether BDNF expression in the DRG is regulated by ERK activation, the immunoreactivity for BDNF in DRG neurons was compared in the vehicle and U0126 groups (Fig. $2 E, F$ ). The MEK1/2 inhibitor U0126 $\left(0.5 \mu \mathrm{g} \cdot \mu \mathrm{l}^{-1} \cdot \mathrm{hr}^{-1}\right)$ significantly inhibited the inflammation-induced increase in BDNF-IR, which was seen mainly in small and medium-sized neurons. BDNF-IR neurons of naive rats in the L4/5 DRG were $12.3 \pm 1.7 \%$ of the total neurons. The percentage of BDNF-IR neurons in the vehicle group $3 \mathrm{~d}$ after the CFA injection was markedly increased to
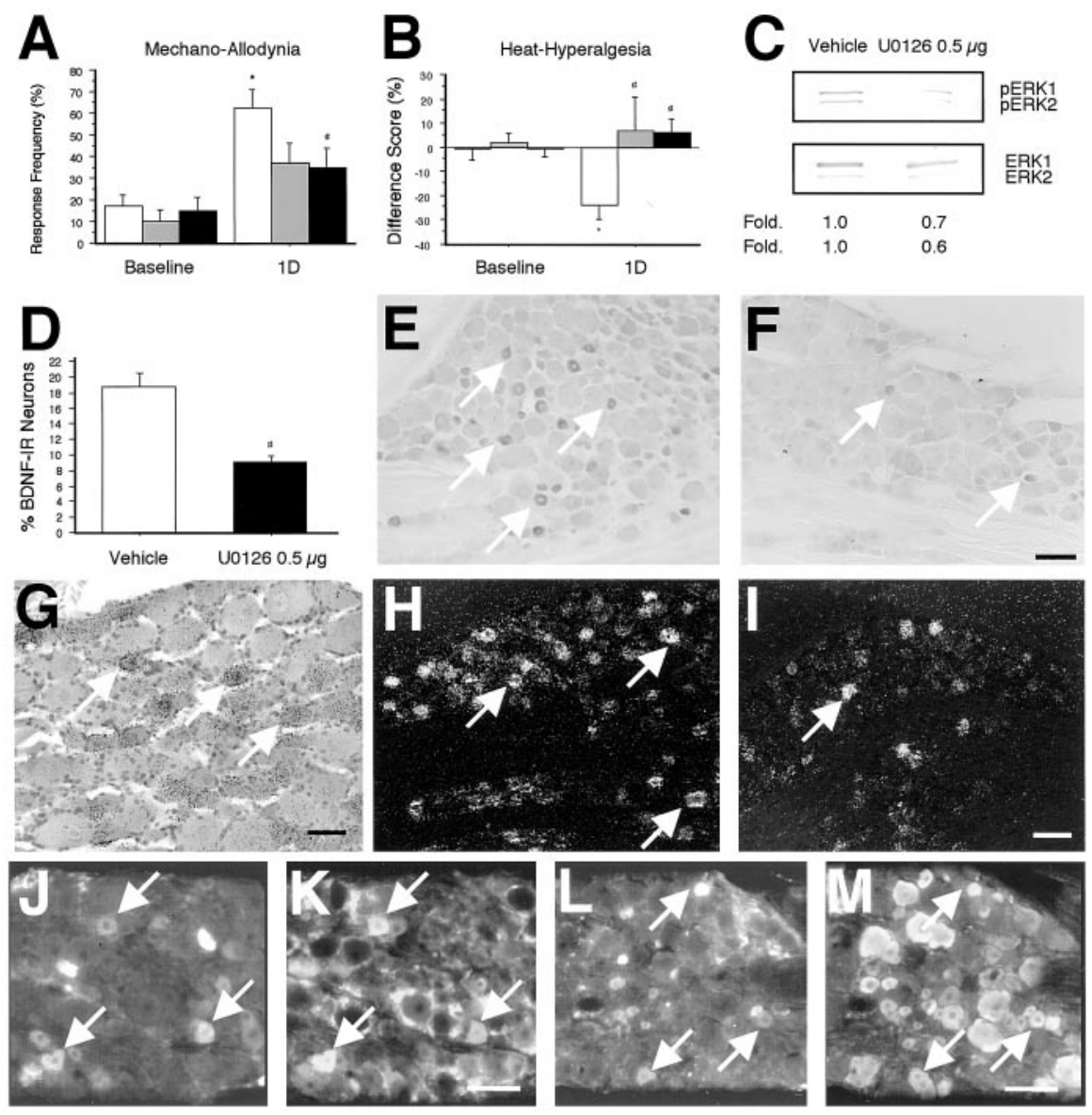

Figure 2. Effects of MEK1/2 inhibitor U0126 delivered intrathecally on CFA-induced inflammatory pain and BDNF expression in the DRG. $A$, The response frequencies of paw withdrawals to repeated mechanical stimuli applied to the pads of the hindpaws with a von Frey filament of $23.0 \mathrm{mN}$ are expressed as a percentage of trials. $B$, The difference score (latency on the operated side from the vehicle group (open columns), the $0.05 \mu \mathrm{g} \cdot \mu \mathrm{l}^{-1} \cdot \mathrm{hr}^{-1}$ U0126 group (gray columns), and the $0.5 \mu \mathrm{g} \cdot \mu \mathrm{l}^{-1} \cdot \mathrm{hr}^{-1}$ group (black columns) at $1 \mathrm{~d}$ after CFA injection are shown (means $\pm \mathrm{SEM}$ ) $\left(n=8\right.$ per group). ${ }^{*} p<0.05$ compared with he DRG at $3 \mathrm{~d}$ was inhibited by MEK inhibitor U0126 delivered by osmotic pump $\left(0.5 \mu \mathrm{g} \cdot \mu \mathrm{l}^{-1} \cdot \mathrm{hr}^{-1}\right)$. E, F, Photomicrographs

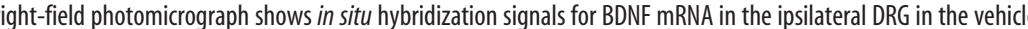

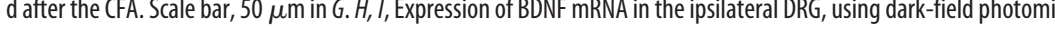
FF and p-ERK in DRG neurons after peripheral inflammation. BDNF-IR $(J)$ and $p$-ERK-IR $(K)$ in the ipsilateral L4/5DRG $3 \mathrm{~d}$ after DRG neurons after peripheral inflammation p-ERK-IR $(L)$ and trkA-IR $(M)$ in the ipsilera labeling of neurons with p-ERK and trkA was observed (L, $M$, arrows). Scale bar: (in I), $H-M, 100 \mu \mathrm{m}$.

$18.9 \pm 1.4 \%$, but U0126 was able to block the effects induced by the CFA $(9.3 \pm 0.8 \%$ ) (Fig. $2 D$ ). To examine whether BDNF immunoreactivity in the DRG neurons represents the level of BDNF synthesis, we studied BDNF mRNA expression in the DRG using ISHH. Consistent with the immunohistochemistry data (Fig. 2E), most neurons labeled for BDNF mRNA were small or medium in size in the vehicle group $3 \mathrm{~d}$ after the CFA (Fig. $2 G$ ). The signals of BDNF mRNA in the ipsilateral DRG neurons in the U0126 group $3 \mathrm{~d}$ after the CFA decreased compared with those of rats in the vehicle group (Fig. $2 H, I$ ). Next, to determine whether the p-ERK-IR neurons and BDNF-expressing neurons belonged to same subset of DRG neurons, we performed double immunofluorescence for p-ERK and BDNF (Fig. 2J,K). In the vehicle group at $3 \mathrm{~d}$ after the CFA injection, p-ERK was detected in a 


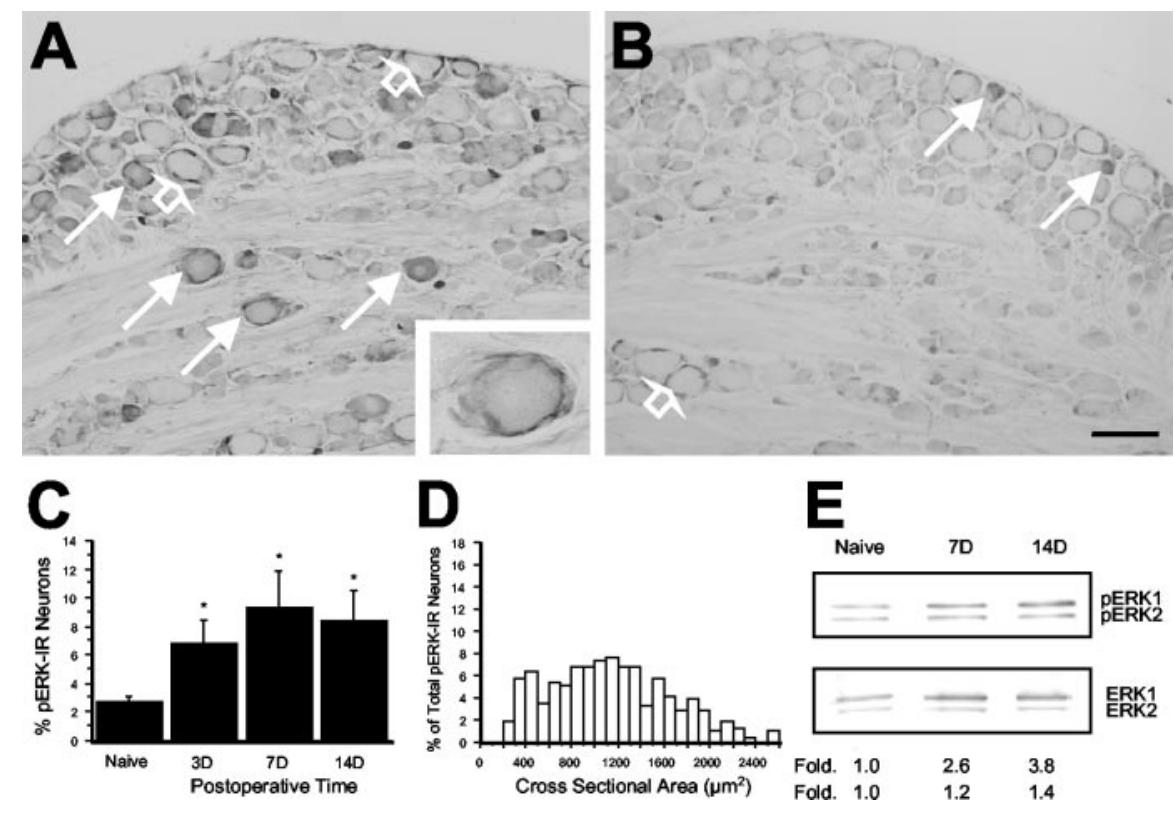

Figure 3. $A, B$, Photomicrographs showing the $p$-ERK-IR in the ipsilateral $(A)$ and contralateral $(B) L 4 / 5$ DRG $7 \mathrm{~d}$ after sciatic nerve transection. Axotomy increased $p$-ERK expression in neurons and/or satellite cells in the ipsilateral DRG. The $p$-ERK-IR was present in both neurons and surrounding satellite cells (large arrows) or only in satellite cells (small open arrows); the inset shows that both the neuron and surrounding satellite cell expressed p-ERK-IR. Scale bar: (in $B$ ) $A, B, 100 \mu \mathrm{m}$. $C$, The time course of the mean percentages of $p$-ERK-IR neurons relative to the total number of neurons in the $L 4 / 5 D R G$. The mean percentages of $p$-ERK-IR neurons on the ipsilateral side significantly increased at 3, 7, and $14 \mathrm{~d}$ after axotomy compared with the naive control rats. ${ }^{*} p<$ 0.05 compared with the naive control. D, Size-distribution histogram of $\mathrm{p}$-ERK-IR neuron profiles in the ipsilateral DRG at $7 \mathrm{~d}$ after axotomy. At least 300 neuron profiles with visible nuclei were counted in four to six randomly chosen sections from two animals (two to three sections per animal). E, Western blot analysis of phosphorylated ERK and total amount of ERK in the ipsilateral L4/5 DRG after axotomy. Axotomy induced an increase in the intensity of the band for p-ERK at 7 and $14 \mathrm{~d}$.

subpopulation of BDNF-labeled neurons $(67.0 \pm 11.4 \% ; n=4)$ and BDNF was detected in $\sim 80 \%$ of p-ERK-labeled cells. Furthermore, to investigate whether the p-ERK neurons also express the high-affinity receptor for NGF, trkA, immunohistochemical colocalization of p-ERK and trkA was examined in the ipsilateral DRG $3 \mathrm{~d}$ after the CFA injection. As shown in Figure $2 L, M$, almost all p-ERK neurons (Fig. $2 L$ ) also expressed trkA-IR (Fig. $2 M)(98.1 \pm 3.9 \% ; n=4)$.

\section{Increase in the phosphorylation of ERK after sciatic nerve transection}

We examined p-ERK immunoreactivity in the DRG after sciatic nerve transection. The number of p-ERK-IR neurons in the ipsilateral DRG markedly increased $7 \mathrm{~d}$ after surgery; the increase in p-ERK-IR was seen mainly in medium- and large-sized neurons (Fig. $3 A, B$ ). In the ipsilateral DRG, the number of p-ERK-IR satellite cells was also greatly increased, particularly around largediameter neurons (Fig. $3 A$ ). The time course of change in the percentage of p-ERK-IR neurons is shown in Figure $3 C$. There was no significant change in the percentage of p-ERK-IR neurons in the contralateral DRG (data not shown). The increase in the percentage of p-ERK-IR neurons in the ipsilateral DRG was first evident at $3 \mathrm{~d}$ after the sciatic nerve lesion $(6.8 \pm 1.7 \%)$ and remained significant at $14 \mathrm{~d}$ after surgery $(8.4 \pm 2.1 \%)$, compared with those of naive control rats. Seven days after the sciatic nerve lesion, 122 of 313 p-ERK-IR neurons counted (39.0\%) were medium-sized and $136(43.5 \%)$ were large, whereas 55 $(17.6 \%)$ were small (mean $\pm \mathrm{SD}$ of the cross-sectional area, $1164 \pm 568 \mu \mathrm{m}^{2}$ ) (Fig. 3D). The size of neurons labeled for p-ERK-IR after sciatic nerve transection was much larger than that of neurons labeled for p-ERK-IR after peripheral inflammation (Fig. 1D) (mean cross-sectional area, $641 \pm 381 \mu \mathrm{m}^{2} ; p<$ 0.001). The L4/5 DRG showed a similar time course of changes in the number of p-ERK-IR-labeled cells. ERK activation by the sciatic nerve lesion was confirmed by Western blot analysis (Fig. 3E). Consistent with the results obtained by immunohistochemistry, the sciatic nerve lesion induced an increase in p-ERK in the ipsilateral DRG at 7 and $14 \mathrm{~d}$ after surgery compared with the naive control.

\section{Colocalization of p-ERK with NF200 or GFAP or ATF3 after sciatic nerve transection}

To investigate whether an increase of p-ERK in a subpopulation of DRG neurons with myelinated fibers occurred after the lesion, we examined immunohistochemical colocalization of $\mathrm{p}$-ERK and NF200, which recognizes a heavy-chain neurofilament found only on cells with myelinated axons (Michael and Priestley, 1999). The results of the colocalization study with p-ERK and NF200 at $7 \mathrm{~d}$ after the lesion are shown in Figure $4 A, B$. The majority of p-ERK neurons (Fig. $4 A$ ) also expressed NF200-IR (Fig. 4B) (83.3 \pm $11.8 \% ; n=4)$. Next, to test whether the p-ERK-IR was associated with glia, colocalization of p-ERK with the glial cell marker GFAP-IR was performed. After sciatic nerve transection, a significant increase in GFAP-IR glial cells was seen, particularly surrounding large neurons (Zhou et al., 1996). As shown in Figure $4 C, D$, the p-ERK-IR was present in ring structures surrounding large neurons and was colocalized with GFAP-IR in the ipsilateral DRG, indicating that a proportion of the p-ERK was localized to satellite glial cells. Furthermore, to determine whether ERK activation after sciatic nerve transection actually takes place in axotomized neurons, we performed doublelabeling experiments for ATF3 expression as a neuronal injury marker. We have reported that ATF3 was induced in DRG neurons that were axotomized after transection of the spinal nerve or sciatic nerve (Tsujino et al., 2000). As shown in Figure 4E,F, we found double labeling of neurons with p-ERK and ATF3, as well as p-ERK expression in satellite glial cells, surrounding largediameter neurons that were labeled for ATF3.

\section{ERK activation mediates autotomy behavior and BDNF expression after sciatic nerve transection}

To elucidate whether the inhibition of ERK activation altered autotomy behavior, the MEK1/2 inhibitor U0126 was delivered intrathecally before sciatic nerve transection via an osmotic pump $\left(0.5 \mu \mathrm{g} \cdot \mu \mathrm{l}^{-1} \cdot \mathrm{hr}^{-1}\right)$ and maintained for $7 \mathrm{~d}$. Rats in the U0126 group at $7 \mathrm{~d}$ after the sciatic nerve lesion showed a significant decrease of the average autotomy score to $0.3 \pm 0.3 \mathrm{com}-$ pared with rats in the vehicle group $(3.1 \pm 0.8)$ (Fig. $5 A$ ). The inhibition of ERK activation by U0126 was confirmed by Western blot analysis (Fig. $5 B$ ). We then examined whether ERK activation is involved in BDNF upregulation after the nerve lesion. The MEK inhibitor U0126 suppressed the axotomy-induced eleva- 

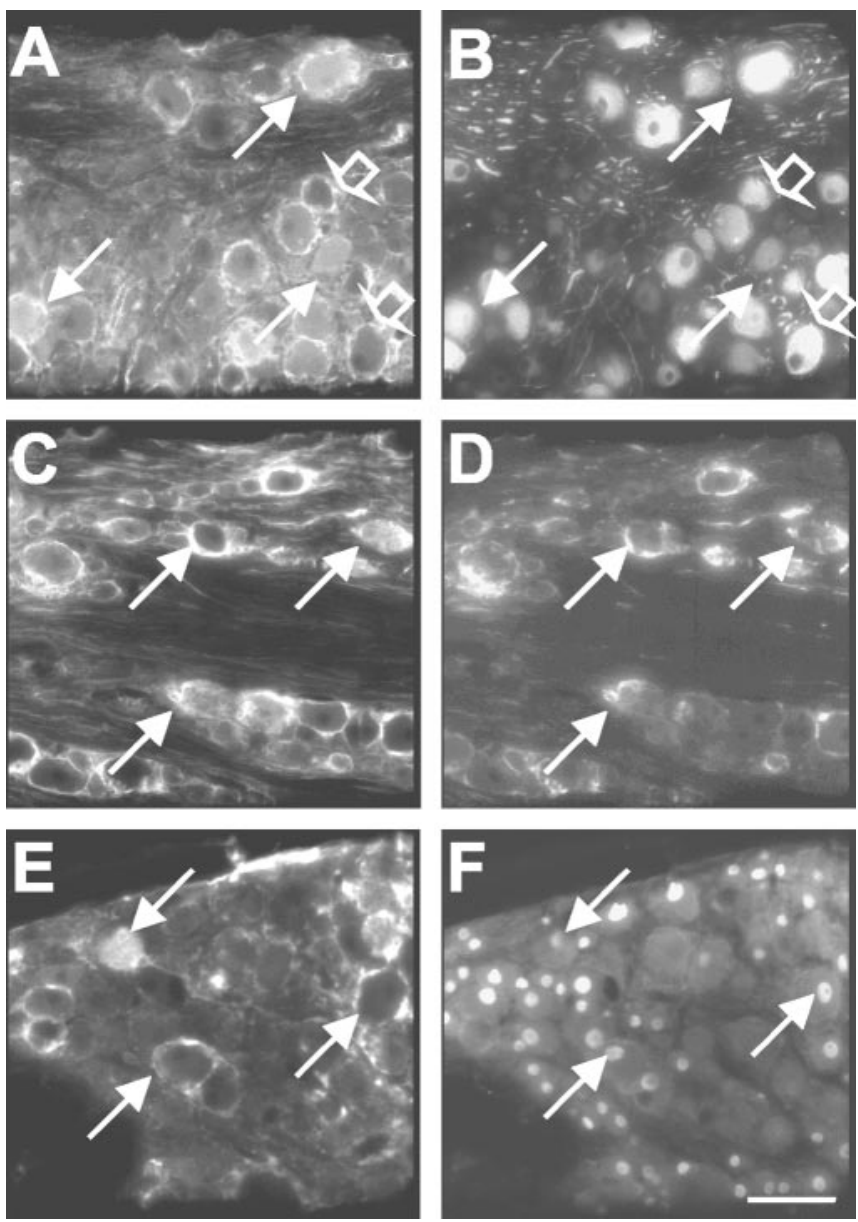

Figure 4. Immunohistochemical colocalization of p-ERK $(A, C, E)$ and $\operatorname{NF200(B),~GFAP~}(D)$, or ATF3 $(F)$ in the ipsilateral L4/5 DRG $7 \mathrm{~d}$ after sciatic nerve transection. Double labeling of neurons with p-ERK and NF200 was detected ( $A, B$, filled arrows). There was also an increase in p-ERK expression in satellite cells, particularly around large-diameter neurons that were positive for NF200 ( $A$, $B$, open arrows). Double labeling of satellite cells with $\mathrm{p}$-ERK and GFAP was detected ( $C, D$, arrows). p-ERK was detected in a subpopulation of ATF3-labeled neurons, and p-ERK-IR was also present in satellite glial cells, surrounding large neurons that were labeled for ATF3-IR (E,F, arrows). Scale bar: (in $F) A-F, 100 \mu \mathrm{m}$.

tion of BDNF-IR in the ipsilateral DRG, which was observed mainly in medium-to-large-diameter sensory neurons (Fig. $5 E, F)$. The neurons labeled for BDNF-IR in the vehicle group $7 \mathrm{~d}$ after the lesion were clearly increased $(26.2 \pm 1.1 \%)$, but the increase in the percentage of BDNF-IR neurons was blocked significantly by this MEK inhibitor (17.6 $\pm 2.4 \%$ ) (Fig. $5 C$ ). To investigate whether U0126 produced a decrease in BDNF expression, with a particularly prominent effect on small neurons, we analyzed the size of neurons labeled for BDNF-IR in the vehicle and U0126 groups. There was no significant difference in the size of neurons labeled for BDNF-IR in the vehicle and U0126 groups (Fig. 5D) (mean cross-sectional areas, $1066 \pm 515$ and $1013 \pm$ $507 \mu \mathrm{m}^{2}$, respectively; $p>0.05$ ), indicating that U0126 blocked the axotomy-induced expression of BDNF in the large neurons as well as BDNF expression in small to medium-sized neurons. Consistent with the immunohistochemistry data (Fig. $5 E$ ), most neurons labeled for BDNF mRNA were medium or large in size in the vehicle group $7 \mathrm{~d}$ after the lesion (Fig. 5G). The decrease in BDNF expression was also confirmed at the mRNA level by ISHH (Fig. 5H,I). Furthermore, to determine whether these p-ERK-IR neurons also expressed BDNF, double immunostaining was per- formed. In the vehicle group $7 \mathrm{~d}$ after the nerve lesion, ERK was activated in a subpopulation of BDNF-labeled neurons (62.5 \pm $6.9 \% ; n=4)$ and BDNF was detected in $\sim 70 \%$ of p-ERK-labeled cells (Fig. 5J,K). As shown in Figure $5 L, M$, trkA was detected in a subpopulation of p-ERK-labeled neurons in the vehicle group $7 \mathrm{~d}$ after the nerve lesion $(75.9 \pm 13.4 \% ; n=4)$.

\section{Effects of intrathecal injections of $\beta$-NGF or anti-NGF on BDNF expression}

To elucidate whether alterations of endogenous NGF can trigger changes in both the phosphorylation of ERK and BDNF expression similar to those seen after peripheral inflammation and peripheral nerve axotomy, intrathecal injections of rat recombinant $\beta$-NGF or anti-NGF (both $10 \mu \mathrm{g}$ in $10 \mu \mathrm{l}$ saline) were performed. The DRG neurons in the NGF group had clear increases in the number of p-ERK-IR, BDNF-IR, and BDNF mRNA-positive neurons (Fig. 6B,E,H) compared with the saline group (Fig. $6 A, D, G) 3 \mathrm{~d}$ after surgery. These p-ERK- and BDNF-labeled neurons were primarily of small or medium diameter. We then quantified the percentage of BDNF-IR neurons $3 \mathrm{~d}$ after injection. The percentage of BDNF-IR neurons $3 \mathrm{~d}$ after $10 \mu \mathrm{g}$ NGF injection was $27.9 \pm 1.8 \%$ of the total number of neurons, which was much higher than the percentage of BDNF-IR neurons in the saline group $(11.5 \pm 0.4 \%$ ) (Fig. $6 J)$. In the NGF group, 176 of 310 BDNF-IR neurons counted (56.8\%) were small and $108(34.8 \%)$ were medium (mean \pm SD of the cross-sectional area, $620 \pm 359$ $\mu \mathrm{m}^{2}$ ) (Fig. $6 \mathrm{~K}$ ). On the other hand, anti-NGF also induced the increase in the number of p-ERK-IR, BDNF-IR, and BDNF mRNA-positive neurons $3 \mathrm{~d}$ after injection, but these p-ERKand BDNF-labeled neurons were medium-to-large-diameter sensory neurons (Fig. 6C,F,I). The p-ERK was located not only in large neuronal cells but also in some surrounding satellite glial cells. These data suggest that NGF antiserum could induce axotomy-like changes in p-ERK and BDNF expression in intact DRG. In the anti-NGF group, the percentage of BDNF-IR neurons $3 \mathrm{~d}$ after injection was $14.7 \pm 2.0 \%$; 117 of 315 BDNF-IR neurons counted $(37.1 \%)$ were medium and $163(51.7 \%)$ were large $\left(1257 \pm 551 \mu \mathrm{m}^{2}\right.$ ) (Fig. 6J,L). The size of neurons labeled for BDNF-IR after the anti-NGF injection was much larger than that of neurons labeled for BDNF-IR after the NGF injection $(p<0.001)$ (Fig. $6 K, L)$. ERK activation by NGF and anti-NGF was also confirmed by Western blot analysis (Fig. 6M). In the anti-NGF group $3 \mathrm{~d}$ after the injection, trkA was detected in a subpopulation of BDNF-labeled neurons ( $41.3 \pm 5.5 \% ; n=3)$ (Fig. 6N,O). Anti-NGF treatment did not affect trkA expression (data not shown).

\section{Discussion}

The present study demonstrated the following new findings: (1) Peripheral inflammation induced an increase in the phosphorylation of ERK in DRG neurons $1 \mathrm{~d}$ after the CFA injection. Most of these p-ERK-IR neurons were small-to-medium-diameter sensory neurons, which coexpressed trkA-IR. (2) Peripheral inflammation produced pain-related behavior on the ipsilateral hindpaw and an increase in the percentage of BDNF-IR neurons in the DRG, but the MEK1/2 inhibitor U0126 was able to block the effects induced by the CFA. (3) Sciatic nerve transection induced an increase in the phosphorylation of ERK in DRG neurons and in satellite glial cells at 3, 7, and $14 \mathrm{~d}$ after the nerve lesion. The increase in p-ERK-IR was seen mainly in mediumand large-sized neurons, which also expressed NF200-IR. (4) Sciatic nerve transection produced autotomy behavior and an increase in the percentage of BDNF-IR neurons in the DRG, but 

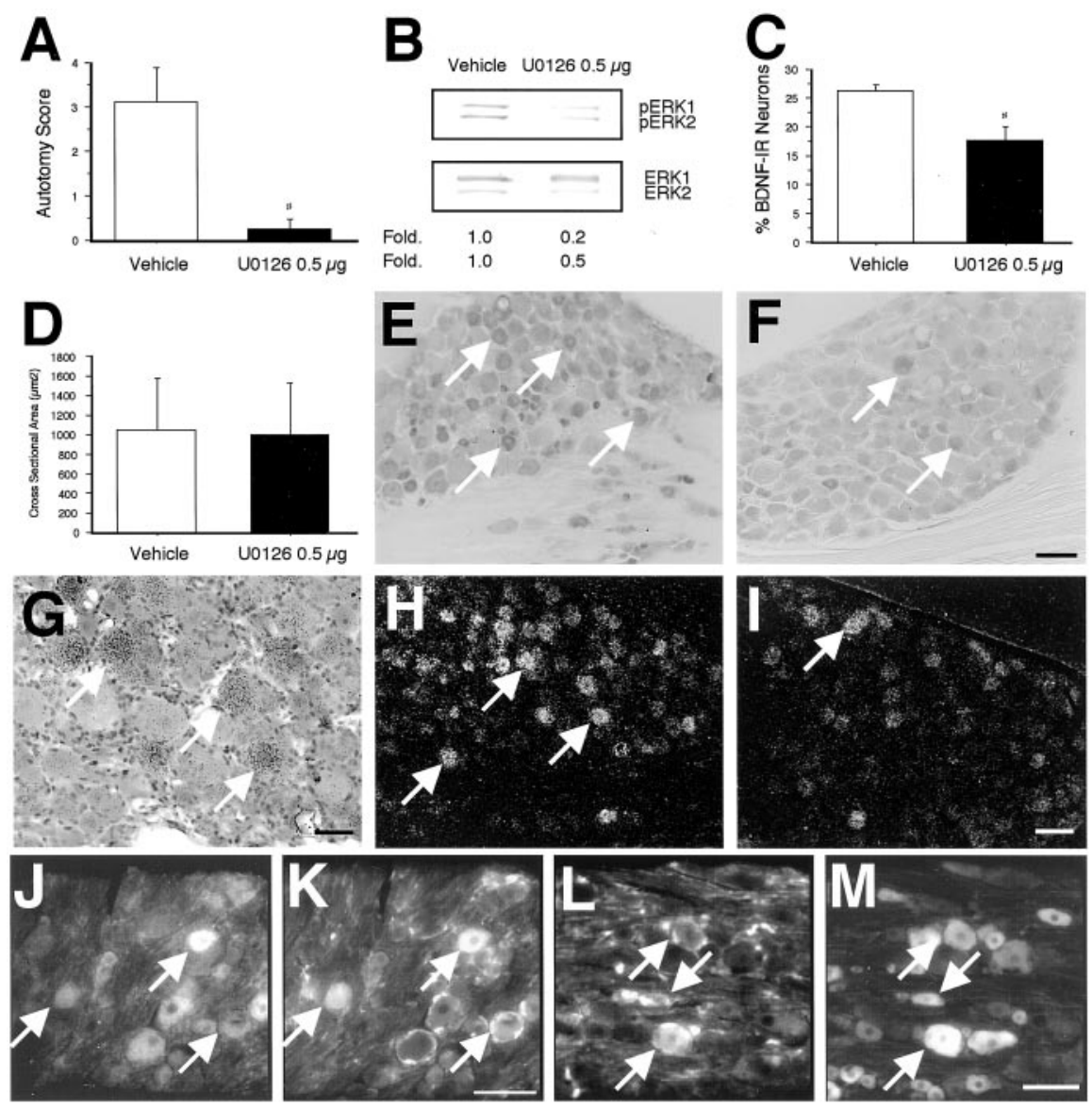

Figure 5. Effects of MEK1/2 inhibitor U0126 delivered intrathecally on axotomy-induced autotomy behavior and BDNF expression in the DRG at $7 \mathrm{~d}$ after surgery. $A$, The autotomy score used is described in the text and the average score achieved by the animals (means \pm SEM) ( $n=8$ per group). ${ }^{*} p<0.05$ compared with vehicle control. $B$, Western blotting indicates that the axotomy-induced ERK activation in the DRG at $7 \mathrm{~d}$ was inhibited by the MEK inhibitor U0126 delivered by osmotic pump ( 0.5 $\left.\mu \mathrm{g} \cdot \mu \mathrm{l}^{-1} \cdot \mathrm{hr}^{-1}\right)$. Both immunohistochemistry $(E, F)$ and in situ hybridization histochemistry $(G-I)$ showed inhibition of the axotomy-induced increase in BDNF-labeled neurons in the DRG by U0126 at $7 \mathrm{~d}$ after surgery. A decrease in the expression of BDNF can be seen in the ipsilateral DRG in the U0126 group $(F, I)$ compared with the vehicle control rats $(E, G, H)$. C, Quantification of the percentage of BDNF-IR neurons at $7 \mathrm{~d}$ after axotomy. ${ }^{\#} p<0.05$ compared with vehicle control. $D$, Mean cross-sectional areas of BDNF-IR neuron profiles in the ipsilateral DRG both in the vehicle and U0126 groups $7 \mathrm{~d}$ after axotomy. At least 300 neuron profiles with visible nuclei were counted in four to six randomly chosen sections from two animals (two to three sections per animal). J, $K$, Immunohistochemical colocalization of BDNF $(J)$ and $p$-ERK $(K)$ in the ipsilateral L4/5 DRG $7 \mathrm{~d}$ after sciatic nerve transection. Some BDNF-IR neurons in the DRG also expressed p-ERK (J, K, arrows). L, M, Immunohistochemistry of p-ERK and trkA in DRG neurons after sciatic nerve transection. $\mathrm{p}$-ERK-IR $(L)$ and $\operatorname{trkA}-\operatorname{IR}(M)$ in the ipsilateral $L 4 / 5 \mathrm{DRG} 7 \mathrm{~d}$ after the nerve lesion are shown. Double labeling of neurons with p-ERK and trkA was observed (L, $M$, arrows). Scale bars: (in $F) E, F, 100 \mu \mathrm{m}$; (in $G$ ) $G, 50 \mu \mathrm{m}$; (in I) $H-M$, $100 \mu \mathrm{m}$.

U0126 inhibited these effects induced by the axotomy. (5) The intrathecal injection of anti-NGF induced an increase in the number of p-ERK- and BDNF-IR neurons at $3 \mathrm{~d}$ after injection, but these p-ERK- and BDNF-IR neurons were medium-to-largediameter sensory neurons, whereas the NGF-induced increase in the number of p-ERK- and BDNF-IR was seen mainly in small and medium-sized neurons.

NGF is suggested to be a major contributor to the production of inflammatory pain (Lewin and Mendell, 1993; Andreev et al., 1995; Bennett et al., 1998). The level of NGF rises substantially in inflamed tissue (Woolf et al., 1996, 1997), and NGF is retrogradely transported to the primary afferent neurons. On the other hand, in vitro studies have characterized many of the intracellular events downstream of trks. For example, the high-affinity receptor for NGF, trkA, can signal through at least six different pathways, a major one of which is a MAPK pathway (i.e., the
ERK1/2 pathway; Finkbeiner, 2000; Chang and Karin, 2001). In this pathway, activated receptors induce GTP loading and activation of the small G-protein Ras. In turn, Ras-GTP recruits a three-tiered enzyme cascade in which a MAPK kinase kinase (Raf) phosphorylates MEK1/2, which phosphorylates and activates ERK1/2 (English et al., 1999). A recent report showed that after either systemic or local NGF treatment, the ERK pathway is activated in DRG neurons and in satellite glial cells in vivo (Averill et al., 2001). In the present study, CFA produced an increased number of p-ERK-IR cells in the DRG. Therefore, we hypothesized that the NGF synthesized and released in the inflamed tissue after peripheral inflammation is transported to the DRG neurons and induces ERK activation in the DRG. Furthermore, p-ERK-IR was observed in neurons containing trkA. This finding is consistent with the well established role for ERK in trkA signaling in vitro (Segal and Greenberg, 1996) and in vivo (Averill et al., 2001).

The present study demonstrated that peripheral inflammation produced heat and mechanical hypersensitivity on the ipsilateral hindpaw and an increased number of BDNF-IR neurons and an increased expression of BDNF mRNA, suggesting increased BDNF synthesis in the DRG. This increase was suppressed by the intrathecal delivery of the MEK1/2 inhibitor U0126. The contribution of NGF to the phenotypic change of DRG neurons has been investigated in several experimental peripheral inflammation models. In addition to SP and CGRP, BDNF synthesis in lumbar DRG neurons has been shown to be regulated by NGF after the intraplantar injection of CFA to the hindpaw (Donnerer et al., 1992; Apfel et al., 1996; Cho et al., 1997a,b). On the other hand, ERK1/2 translocates from the cytoplasm to the nucleus and activates Rsk2, which then phosphorylates the transcription factor CREB on serine 133 (Xing et al., 1996). The phosphorylated CREB then binds to the CRE sites on the promoter regions of the DNA and initiates the transcription of genes, such as c-fos, dynorphin, and BDNF (Shieh et al., 1998; Bonni et al., 1999; Riccio et al., 1999; Finkbeiner, 2000). Taken together, these observations suggest that the activation of the ERK pathway is a key intracellular signaling event in the NGF-induced increase in the expression of BDNF in the peripheral inflammation model. To examine this issue further, a small volume of NGF was injected intrathecally. We found that NGF injection produced an increase in the phosphorylation of ERK in the DRG and also an increase in the percentage of BDNF-IR neurons in the DRG.

The increased p-ERK expression that occurred after axotomy appeared mainly in medium- and large-sized neurons. Thus, the changes after axotomy contrast starkly with the massive p-ERK 
increase in trkA-containing small neurons that occurs with NGF treatment (Averill et al., 2001) and also peripheral inflammation in this study. Furthermore, p-ERK expression was also upregulated in satellite glial cells that surrounded, in particular, the larger-diameter neuronal somata. It is not known whether this effect is direct or indirect, but it emphasizes the importance of glial cells and glial-neuronal interactions after axotomy. In the present study, sciatic nerve transection produced autotomy behavior. Although autotomy (self-mutilation behavior) may be a response to a painless or anesthetic limb, which is no longer perceived as self (Sweet, 1981; Rodin and Kruger, 1984), and the mechanisms of autotomy remain largely unknown, several reports have suggested that autotomy in animals after nerve injury is a reaction related to painful sensations (Wall et al., 1979; Coderre et al., 1986; Janig and McLachlan, 1992). Considering that U0126 blocked axotomy-produced ERK activation and autotomy behavior, it is suggested that the ERK pathway in the DRG might be involved in the pathophysiology of neuropathic pain, as well as painful inflammation. Our results in the DRG are new findings, but Woolf and colleagues (Ji et al., 2002a) recently demonstrated that the activation of the ERK in dorsal horn neurons contributes to persistent inflammatory pain. Therefore, the effects of U0126 on pathological pain could also be mediated by the inhibition of ERK activation in dorsal horn neurons.

The pathophysiological mechanisms of the phosphorylation of ERK and the increase in BDNF that occur in the axotomized medium-to-large-diameter DRG neurons are not clear at this point. The reduction in endogenous NGF may be important for triggering a variety of changes in neuropeptides after axotomy, because exogenous NGF can reverse these changes (Verge et al., 1995); also, an antiserum against NGF can trigger changes in peptide expression similar to those seen after axotomy (Shadiack et al., 2001). An interesting finding in the present study was that the intrathecal injection of antiNGF, as well as the axotomy, induced an increased expression of $\mathrm{p}$-ERK and BDNF in trkA-expressing medium-to-largediameter neurons. Previous papers reported that a subpopulation of medium- and large-sized DRG neurons contained trkA (Molliver et al., 1995; Bergman et al., 1999; Karchewski et al., 1999) and also that axotomy induced an increase in BDNF expression in trkA-expressing large-diameter neurons, as well as trkB- and trkC-expressing large neurons (Michael et al., 1999). Therefore, the expression
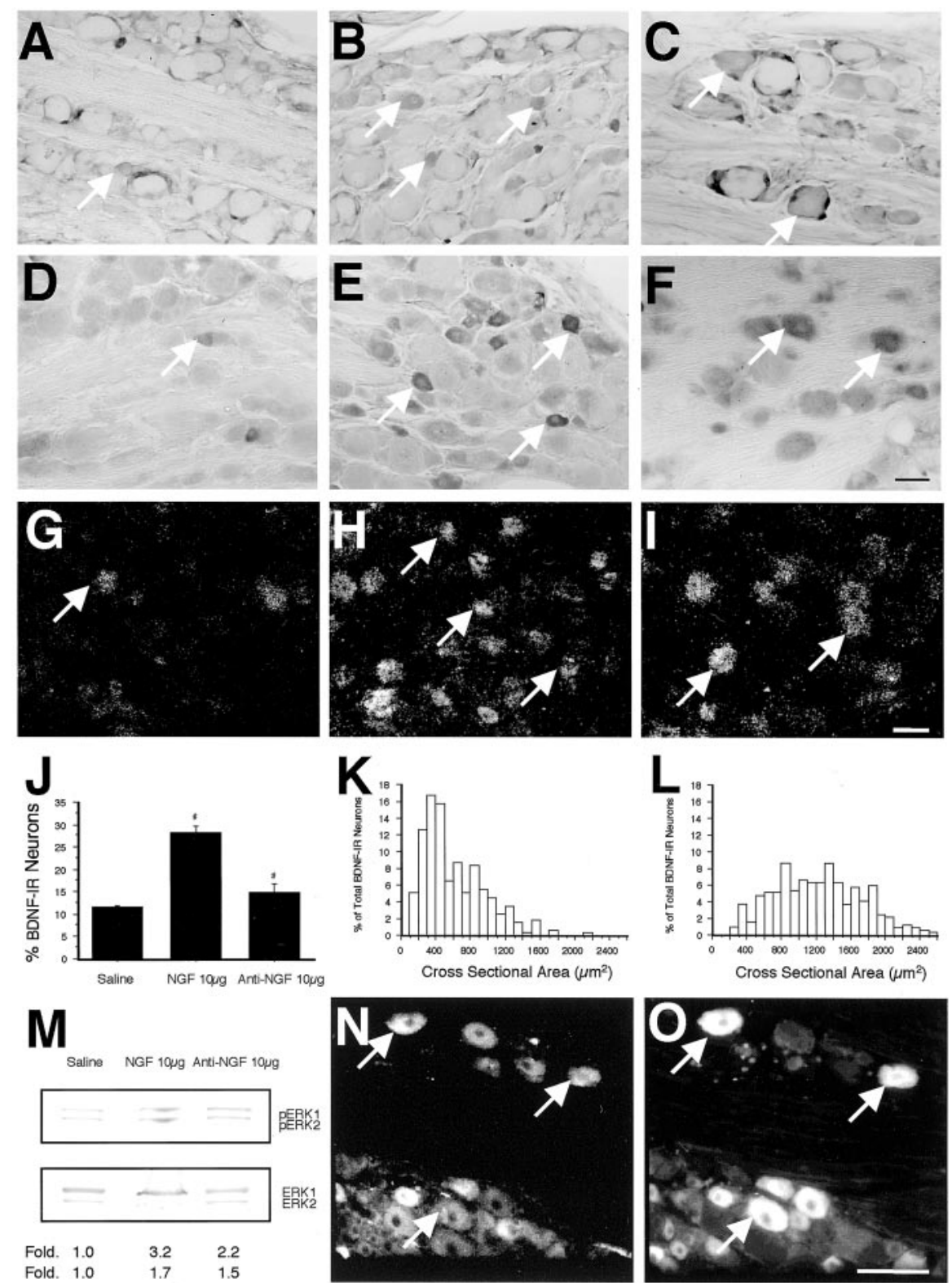

Figure 6. Effects of intrathecal injections of recombinant rat $\beta$-NGF or anti-NGF on the increase in the phosphorylation of ERK and BDNF expression in the DRG $3 \mathrm{~d}$ after surgery. Photomicrographs showing the $\mathrm{p}-\mathrm{ERK}-\mathrm{IR}(A-C), \mathrm{BDNF}-\mathrm{IR}(D-F)$, and BDNF mRNA-positive $(G-I)$ neurons in the $L 4 / 5$ DRG $3 \mathrm{~d}$ after surgery. The DRG neurons in the $10 \mu \mathrm{g} \mathrm{NGF}$ group had clear increases in the number of both $p$-ERK- and BDNF-labeled neurons $(B, E, H)$, compared with the saline group $(A, D, G), 3 \mathrm{~d}$ after surgery. Most of these $\mathrm{p}$-ERK- and BDNF-positive neurons were small-to-medium-diameter sensory neurons, as indicated by arrows in $B, E$, and $H$, respectively. An increase in the number of $p$-ERK- and BDNF-labeled neurons was detected in the $10 \mu \mathrm{g}$ anti-NGF group $(C, F, I)$ compared with the saline group $(A, D, G) 3 \mathrm{~d}$ after surgery. The anti-NGF-induced increase in $\mathrm{p}$-ERK and BDNF expression was seen mainly in medium- and large-sized neurons ( $C, F$, and $I$, respectively). Scale bar: (in I) $A-I, 50 \mu \mathrm{m}$. J, Quantification of the percentage of BDNF-IR neurons 3 d after the injection. ${ }^{\#} p<0.05$ compared with the saline group. $K, L$, Size-distribution histograms of BDNF-IR neuron profiles $3 \mathrm{~d}$ after the injection in the $10 \mu \mathrm{g} \mathrm{NGF}$ and $10 \mu \mathrm{g}$ anti-NGF groups are shown in Kand L, respectively. At least 300 neuron profiles with visible nuclei were counted in four to six randomly chosen sections from two animals (two to three sections per animal). $M$, Western blot analysis of phosphorylated ERK and total amount of ERK in the L4/5 DRG after the intrathecal injection of NGF and anti-NGF. NGF and anti-NGF induced an increase in the intensity of the band for p-ERK at $1 \mathrm{~d}$. Bottom, Levels of total ERK, as loading controls. $N, 0$, Immunohistochemical colocalization of BDNF $(N)$ and trkA $(0)$ in the L4/5 DRG in the anti-NGF $10 \mu$ group at $3 \mathrm{~d}$. Some BDNF-IR neurons in the DRG also expressed trkA (N, O, arrows). Scale bar: (in 0) N, $0,100 \mu \mathrm{m}$. of p-ERK and BDNF in trkA-expressing medium- and largesized neurons may be regulated negatively by NGF, although additional investigations will be needed. Alternatively, the increased expression of BDNF in trkB- or trkC-expressing largediameter neurons after ERK activation could be regulated negatively by a target-derived factor acting through trkB or trkC, such 
as neurotrophin-3 (Ohara et al., 1995), or positively by other injury-induced factors, such as leukemia inhibitory factor (Banner and Patterson, 1994; Curtis et al., 1994; Sun et al., 1994, 1996).

In the present study, the percentages of p-ERK-IR neurons in both pain states were small, and double-staining experiments revealed that a subpopulation of BDNF-IR neurons was p-ERKexpressing. It is likely that other MAPK pathways, such as P38, c-jun N-terminal kinase, or ERK5 pathways, also may be activated by inflammation and/or nerve injury (Kenney and Kocsis, 1998; Watson et al., 2001; Ji et al., 2002b). However, Woolf and colleagues suggested the possible signal cascade from the phosphorylated ERK to the activation of the transcription factor CREB, which initiates the transcription of the BDNF (Woolf and Costigan, 1999; Ji and Woolf, 2001). Recent reports suggested a role of ERK signaling in another form of neural plasticity, namely sensitization of nociceptors (Aley et al., 2001; Dai et al., 2002). BDNF that is synthesized in the DRG is transported to the central terminals of the primary afferents in the spinal dorsal horn (Zhou and Rush, 1996), is released, and acts on the trkB receptor on second-order sensory neurons, in which BDNF is involved in the modulation of painful stimuli (Kafitz et al., 1999; Mannion et al., 1999; Lever et al., 2001). Exogenous BDNF enhances NMDAinduced depolarizations in the spinal cord: a mechanism of central sensitization (Kerr et al., 1999). Although additional studies will be required to establish whether the increased BDNF synthesis in the DRG after ERK activation underlies the sensitization of primary afferent neurons, these findings suggest that MAPK signaling plays an important role in pain states evoked by several different mediators and pathological conditions.

\section{References}

Aley KO, Martin A, McMahon T, Mok J, Levine JD, Messing RO (2001) Nociceptor sensitization by extracellular signal-regulated kinases. J Neurosci 21:6933-6939.

Andreev NY, Dimitrieva N, Koltzenburg M, McMahon SB (1995) Peripheral administration of nerve growth factor in the adult rat produces a thermal hyperalgesia that requires the presence of sympathetic postganglionic neurones. Pain 63:109-115.

Apfel SC, Wright DE, Wiideman AM, Dormia C, Snider WD, Kessler JA (1996) Nerve growth factor regulates the expression of brain-derived neurotrophic factor mRNA in the peripheral nervous system. Mol Cell Neurosci 7:134-142.

Atkins CM, Selcher JC, Petraitis JJ, Trzaskos JM, Sweatt JD (1998) The MAPK cascade is required for mammalian associative learning. Nat Neurosci 1:602-609.

Averill S, Delcroix JD, Michael GJ, Tomlinson DR, Fernyhough P, Priestley JV (2001) Nerve growth factor modulates the activation status and fast axonal transport of erk 1/2 in adult nociceptive neurones. Mol Cell Neurosci 18:183-196.

Banner LR, Patterson PH (1994) Major changes in the expression of the mRNAs for cholinergic differentiation factor/leukemia inhibitory factor and its receptor after injury to adult peripheral nerves and ganglia. Proc Natl Acad Sci USA 91:7109-7113.

Bennett G, al-Rashed S, Hoult JR, Brain SD (1998) Nerve growth factor induced hyperalgesia in the rat hind paw is dependent on circulating neutrophils. Pain 77:315-322.

Bergman E, Fundin BT, Ulfhake B (1999) Effects of aging and axotomy on the expression of neurotrophin receptors in primary sensory neurons. J Comp Neurol 410:368-386.

Bileviciute-Ljungar I, Lundeberg T (2000) Contralateral treatment with xylocaine reduces nociceptive behaviour in mononeuropathic rats. NeuroReport 11:291-295.

Bonni A, Brunet A, West AE, Datta SR, Takasu MA, Greenberg ME (1999) Cell survival promoted by the Ras-MAPK signaling pathway by transcription-dependent and -independent mechanisms. Science 286:1358-1362.

Chang L, Karin M (2001) Mammalian MAP kinase signalling cascades. Nature 410:37-40.
Cho HJ, Kim SY, Park MJ, Kim DS, Kim JK, Chu MY (1997a) Expression of mRNA for brain-derived neurotrophic factor in the dorsal root ganglion following peripheral inflammation. Brain Res 749:358-362.

Cho HJ, Kim JK, Zhou XF, Rush RA (1997b) Increased brain-derived neurotrophic factor immunoreactivity in rat dorsal root ganglia and spinal cord following peripheral inflammation. Brain Res 764:269-272.

Cho HJ, Kim JK, Park HC, Kim JK, Kim DS, Ha SO, Hong HS (1998) Changes in brain-derived neurotrophic factor immunoreactivity in rat dorsal root ganglia, spinal cord, and gracile nuclei following cut or crush injuries. Exp Neurol 154:224-230.

Coderre TJ, Grimes RW, Melzack R (1986) Deafferentation and chronic pain in animals: an evaluation of evidence suggesting autotomy is related to pain. Pain 26:61-84.

Curtis R, Scherer SS, Somogyi R, Adryan KM, Ip NY, Zhu Y, Lindsay RM, DiStefano PS (1994) Retrograde axonal transport of LIF is increased by peripheral nerve injury: correlation with increased LIF expression in distal nerve. Neuron 12:191-204.

Dai Y, Iwata K, Fukuoka T, Kondo E, Tokunaga A, Yamanaka H, Tachibana T, Liu Y, Noguchi K (2002) Phosphorylation of extracellular signalregulated kinase in primary afferent neurons by noxious stimuli and its involvement in peripheral sensitization. J Neurosci 22:7737-7745.

Delcroix JD, Averill S, Fernandes K, Tomlinson DR, Priestley JV, Fernyhough P (1999) Axonal transport of activating transcription factor-2 is modulated by nerve growth factor in nociceptive neurons. J Neurosci 19:RC24(1-7).

Donnerer J, Schuligoi R, Stein C (1992) Increased content and transport of substance $\mathrm{P}$ and calcitonin gene-related peptide in sensory nerves innervating inflamed tissue: evidence for a regulatory function of nerve growth factor in vivo. Neuroscience 49:693-698.

English JD, Sweatt JD (1997) A requirement for the mitogen-activated protein kinase cascade in hippocampal long term potentiation. J Biol Chem 272:19103-19106.

English J, Pearson G, Wilsbacher J, Swantek J, Karandikar M, Xu S, Cobb MH (1999) New insights into the control of MAP kinase pathways. Exp Cell Res 253:255-270.

Finkbeiner S (2000) CREB couples neurotrophin signals to survival messages. Neuron 25:11-14.

Fukuoka T, Kondo E, Dai Y, Hashimoto N, Noguchi K (2001) Brainderived neurotrophic factor increases in the uninjured dorsal root ganglion neurons in selective spinal nerve ligation model. J Neurosci 21:4891-4900.

Hashimoto N, Yamanaka H, Fukuoka T, Dai Y, Obata K, Mashimo T, Noguchi K (2001) Expression of HGF and cMet in the peripheral nervous system of adult rats following sciatic nerve injury. NeuroReport 12:1403-1407.

Hokfelt T, Zhang X, Wiesenfeld-Hallin Z (1994) Messenger plasticity in primary sensory neurons following axotomy and its functional implications. Trends Neurosci 17:22-30.

Impey S, Obrietan K, Wong ST, Poser S, Yano S, Wayman G, Deloulme JC, Chan G, Storm DR (1998) Cross talk between ERK and PKA is required for $\mathrm{Ca}^{2+}$ stimulation of CREB-dependent transcription and ERK nuclear translocation. Neuron 21:869-883.

Impey S, Obrietan K, Storm DR (1999) Making new connections: role of ERK/MAP kinase signaling in neuronal plasticity. Neuron 23:11-14.

Janig W, McLachlan EM (1992) Characteristics of function-specific pathways in the sympathetic nervous system. Trends Neurosci 15:475-481.

Ji RR, Woolf CJ (2001) Neuronal plasticity and signal transduction in nociceptive neurons: implications for the initiation and maintenance of pathological pain. Neurobiol Dis 8:1-10.

Ji RR, Befort K, Brenner GJ, Woolf CJ (2002a) ERK MAP kinase activation in superficial spinal cord neurons induces prodynorphin and NK-1 upregulation and contributes to persistent inflammatory pain hypersensitivity. J Neurosci 22:478-485.

Ji RR, Samad TA, Jin SX, Schmoll R, Woolf CJ (2002b) p38 MAPK activation by NGF in primary sensory neurons after inflammation increases TRPV1 levels and maintains heat hyperalgesia. Neuron 36:57-68.

Kafitz KW, Rose CR, Thoenen H, Konnerth A (1999) Neurotrophin-evoked rapid excitation through TrkB receptors. Nature 401:918-921.

Karchewski LA, Kim FA, Johnston J, McKnight RM, Verge VM (1999) Anatomical evidence supporting the potential for modulation by multiple neurotrophins in the majority of adult lumbar sensory neurons. J Comp Neurol 413:327-341. 
Kenney AM, Kocsis JD (1998) Peripheral axotomy induces long-term c-Jun amino-terminal kinase-1 activation and activator protein-1 binding activity by c-Jun and junD in adult rat dorsal root ganglia in vivo. J Neurosci 18:1318-1328.

Kerr BJ, Bradbury EJ, Bennett DL, Trivedi PM, Dassan P, French J, Shelton DB, McMahon SB, Thompson SW (1999) Brain-derived neurotrophic factor modulates nociceptive sensory inputs and NMDA-evoked responses in the rat spinal cord. J Neurosci 19:5138-5148.

Lever IJ, Bradbury EJ, Cunningham JR, Adelson DW, Jones MG, McMahon SB, Marvizon JC, Malcangio M (2001) Brain-derived neurotrophic factor is released in the dorsal horn by distinctive patterns of afferent fiber stimulation. J Neurosci 21:4469-4477.

Lewin GR, Mendell LM (1993) Nerve growth factor and nociception. Trends Neurosci 16:353-359.

Lewis TS, Shapiro PS, Ahn NG (1998) Signal transduction through MAP kinase cascades. Adv Cancer Res 74:49-139.

Li WP, Xian C, Rush RA, Zhou XF (1999) Upregulation of brain-derived neurotrophic factor and neuropeptide $\mathrm{Y}$ in the dorsal ascending sensory pathway following sciatic nerve injury in rat. Neurosci Lett 260:49-52.

Ma W, Zheng WH, Powell K, Jhamandas K, Quirion R (2001) Chronic morphine exposure increases the phosphorylation of MAP kinases and the transcription factor CREB in dorsal root ganglion neurons: an in vitro and in vivo study. Eur J Neurosci 14:1091-1104.

Mannion RJ, Costigan M, Decosterd I, Amaya F, Ma QP, Holstege JC, Ji RR, Acheson A, Lindsay RM, Wilkinson GA, Woolf CJ (1999) Neurotrophins: peripherally and centrally acting modulators of tactile stimulusinduced inflammatory pain hypersensitivity. Proc Natl Acad Sci USA 96:9385-9390.

Michael GJ, Priestley JV (1999) Differential expression of the mRNA for the vanilloid receptor subtype 1 in cells of the adult rat dorsal root and nodose ganglia and its downregulation by axotomy. J Neurosci 19:1844-1854.

Michael GJ, Averill S, Nitkunan A, Rattray M, Bennett DL, Yan Q, Priestley JV (1997) Nerve growth factor treatment increases brain-derived neurotrophic factor selectively in TrkA-expressing dorsal root ganglion cells and in their central terminations within the spinal cord. J Neurosci 17:8476-8490.

Michael GJ, Averill S, Shortland PJ, Yan Q, Priestley JV (1999) Axotomy results in major changes in BDNF expression by dorsal root ganglion cells: BDNF expression in large trkB and trkC cells, in pericellular baskets, and in projections to deep dorsal horn and dorsal column nuclei. Eur J Neurosci 11:3539-3551.

Miki K, Fukuoka T, Tokunaga A, Kondo E, Dai Y, Noguchi K (2000) Differential effect of brain-derived neurotrophic factor on high-threshold mechanosensitivity in a rat neuropathic pain model. Neurosci Lett 278:85-88.

Molliver DC, Radeke MJ, Feinstein SC, Snider WD (1995) Presence or absence of TrkA protein distinguishes subsets of small sensory neurons with unique cytochemical characteristics and dorsal horn projections. J Comp Neurol 361:404-416.

Noguchi K, Kawai Y, Fukuoka T, Senba E, Miki K (1995) Substance P induced by peripheral nerve injury in primary afferent sensory neurons and its effect on dorsal column nucleus neurons. J Neurosci 15:7633-7643.

Obata K, Tsujino H, Yamanaka H, Dai Y, Fukuoka T, Hashimoto N, Yonenobu K, Yoshikawa H, Noguchi K (2002) Expression of neurotrophic factors in the dorsal root ganglion in a rat model of lumbar disc herniation. Pain 99:121-132.

Obata K, Yamanaka H, Fukuoka T, Dai Y, Tokunaga A, Hashimoto N, Yoshikawa H, Noguchi K (2003) Contribution of injured and uninjured DRG neurons to pain behavior and the changes in gene expression following chronic constriction injury of the sciatic nerve in rats. Pain 101:65-77.

Obrietan K, Impey S, Smith D, Athos J, Storm DR (1999) Circadian regulation of cAMP response element-mediated gene expression in the suprachiasmatic nuclei. J Biol Chem 274:17748-17756.

Ohara S, Tantuwaya V, DiStefano PS, Schmidt RE (1995) Exogenous NT-3 mitigates the transganglionic neuropeptide $\mathrm{Y}$ response to sciatic nerve injury. Brain Res 699:143-148.

Riccio A, Ahn S, Davenport CM, Blendy JA, Ginty DD (1999) Mediation by a CREB family transcription factor of NGF-dependent survival of sympathetic neurons. Science 286:2358-2361.

Rodin BE, Kruger L (1984) Deafferentation in animals as a model for the study of pain: an alternative hypothesis. Brain Res 319:213-228.
Segal RA, Greenberg ME (1996) Intracellular signaling pathways activated by neurotrophic factors. Annu Rev Neurosci 19:463-489.

Sgambato V, Pages C, Rogard M, Besson MJ, Caboche J (1998) Extracellular signal-regulated kinase (ERK) controls immediate early gene induction on corticostriatal stimulation. J Neurosci 18:8814-8825.

Shadiack AM, Sun Y, Zigmond RE (2001) Nerve growth factor antiserum induces axotomy-like changes in neuropeptide expression in intact sympathetic and sensory neurons. J Neurosci 21:363-371.

Shieh PB, Hu SC, Bobb K, Timmusk T, Ghosh A (1998) Identification of a signaling pathway involved in calcium regulation of BDNF expression. Neuron 20:727-740.

Sun Y, Rao MS, Zigmond RE, Landis SC (1994) Regulation of vasoactive intestinal peptide expression in sympathetic neurons in culture and after axotomy: the role of cholinergic differentiation factor/leukemia inhibitory factor. J Neurobiol 25:415-430.

Sun Y, Landis SC, Zigmond RE (1996) Signals triggering the induction of leukemia inhibitory factor in sympathetic superior cervical ganglia and their nerve trunks after axonal injury. Mol Cell Neurosci 7:152-163.

Sweet WH (1981) Animal models of chronic pain: their possible validation from human experience with posterior rhizotomy and congenital analgesia (Part I of the second John J. Bonica lecture). Pain 10:275-295.

Thompson SW, Bennett DL, Kerr BJ, Bradbury EJ, McMahon SB (1999) Brainderived neurotrophic factor is an endogenous modulator of nociceptive responses in the spinal cord. Proc Natl Acad Sci USA 96:7714-7718.

Tonra JR, Curtis R, Wong V, Cliffer KD, Park JS, Timmes A, Nguyen T, Lindsay RM, Acheson A, DiStefano PS (1998) Axotomy upregulates the anterograde transport and expression of brain-derived neurotrophic factor by sensory neurons. J Neurosci 18:4374-4383.

Tsujino H, Kondo E, Fukuoka T, Dai Y, Tokunaga A, Miki K, Yonenobu K, Ochi T, Noguchi K (2000) Activating transcription factor 3 (ATF3) induction by axotomy in sensory and motoneurons: a novel neuronal marker of nerve injury. Mol Cell Neurosci 15:170-182.

Verge VM, Richardson PM, Wiesenfeld-Hallin Z, Hokfelt T (1995) Differential influence of nerve growth factor on neuropeptide expression in vivo: a novel role in peptide suppression in adult sensory neurons. J Neurosci 15:2081-2096.

Wall PD, Devor M, Inbal R, Scadding JW, Schonfeld D, Seltzer Z, Tomkiewicz MM (1979) Autotomy following peripheral nerve lesions: experimental anaesthesia dolorosa. Pain 7:103-111.

Watson FL, Heerssen HM, Bhattacharyya A, Klesse L, Lin MZ, Segal RA (2001) Neurotrophins use the Erk5 pathway to mediate a retrograde survival response. Nat Neurosci 4:981-988.

Wiesenfeld Z, Hallin RG (1983) Continuous naloxone administration via osmotic minipump decreases autotomy but has no effect on nociceptive threshold in the rat. Pain 16:145-153.

Woolf CJ, Costigan M (1999) Transcriptional and posttranslational plasticity and the generation of inflammatory pain. Proc Natl Acad Sci USA 96:7723-7730.

Woolf CJ, Salter MW (2000) Neuronal plasticity: increasing the gain in pain. Science 288:1765-1769.

Woolf CJ, Ma QP, Allchorne A, Poole S (1996) Peripheral cell types contributing to the hyperalgesic action of nerve growth factor in inflammation. J Neurosci 16:2716-2723.

Woolf CJ, Allchorne A, Safieh-Garabedian B, Poole S (1997) Cytokines, nerve growth factor and inflammatory hyperalgesia: the contribution of tumour necrosis factor $\alpha$. Br J Pharmacol 121:417-424.

Xing J, Ginty DD, Greenberg ME (1996) Coupling of the RAS-MAPK pathway to gene activation by RSK2, a growth factor-regulated CREB kinase. Science 273:959-963.

Yamanaka H, He X, Matsumoto K, Shiosaka S, Yoshida S (1999) Protease $\mathrm{M} /$ neurosin mRNA is expressed in mature oligodendrocytes. Brain Res Mol Brain Res 71:217-224.

Zhou XF, Rush RA (1996) Endogenous brain-derived neurotrophic factor is anterogradely transported in primary sensory neurons. Neuroscience 74:945-953.

Zhou XF, Rush RA, McLachlan EM (1996) Differential expression of the p75 nerve growth factor receptor in glia and neurons of the rat dorsal root ganglia after peripheral nerve transection. J Neurosci 16:2901-2911.

Zhou XF, Chie ET, Deng YS, Zhong JH, Xue Q, Rush RA, Xian CJ (1999) Injured primary sensory neurons switch phenotype for brain-derived neurotrophic factor in the rat. Neuroscience 92:841-853. 